\title{
Explicit Grammar Instruction for EFL Writing and Editing: An Exploratory Study at a Korean University
}

\author{
Grace H. Wang ${ }^{1, *}$, Seok-Dong Wang ${ }^{2}$ \\ ${ }^{1}$ University College, Yonsei University, Seoul, 120-749, Republic of Korea \\ ${ }^{2}$ Division of International Studies, Hankuk University of Foreign Studies, Seoul, 130-791, Republic of Korea \\ *Corresponding Author: ghwang97@yonsei.ac.kr
}

Copyright $(2014$ Horizon Research Publishing All rights reserved.

\begin{abstract}
One of the most difficult areas to address in required college English classes for students and teachers alike is composition accuracy at the sentential level, that is, sentence grammar. The purpose of this study is to explore the effect of explicit grammar instruction on Korean students' perceptions of their writing and editing skills at the sentential level in a freshman reading and writing course. The study participants comprised of 15 students enrolled in a required intermediate-level freshman English reading and writing course during the winter vacation semester at a top-ranking university in Seoul. The students completed a pre-intervention writing assignment prior to receiving sentence grammar instruction, and a similar but slightly different post-intervention assignment after receiving the instruction. The intervention was provided in the form of a set of workbooks which the students read and studied for homework over a period of a week. Aside from answering students' questions on the workbooks, no other sentence grammar instruction was provided. Upon submitting the post-intervention writing assignment, the students completed an online survey anonymously to reflect on their experience of the overall task. The results of the survey point to a positive impact of the intervention on the participants' perceptions of their writing and editing abilities. This study is significant for raising the issue that explicit grammar instruction delivered in the form of workbooks could have a beneficial role in foreign language writing pedagogy.
\end{abstract}

Keywords Explicit Grammar Instruction, EFL Writing, Peer-Editing, College English, Korean Learners

\section{Introduction}

One of the most difficult areas to address in required college English classes for students and teachers alike is composition accuracy at the sentential level, that is, sentence grammar. Part of the reason for this is that required college English classes in EFL contexts like South Korea are often at least two-skills focused, if not four, and they are commonly not devoted solely to the development of writing skills. With class time being a precious commodity, teachers may often find it difficult to allocate a lot of attention to providing grammar lessons. In addition, most university students in South Korea study laboriously as high school students to write university entrance examinations, and one of the subjects they are required to master for these examinations is English grammar. Hence, many college English instructors, especially in Korea, as well as the students themselves, tend to feel that freshman students have had enough grammar instruction, thereby attending to other aspects of writing skills development, such as paragraph and essay organization.

The scholarly literature on the role and efficacy of explicit grammar instruction in writing pedagogy, especially in the ESL or EFL (L2) settings, is bereft of information. Although the place of grammar in the school curriculum has been the topic of much heated debate and controversy in public and academic arenas for more than 50 years, it has been noted over and over again that good, reliable evidence is wanting in this area of investigation (Andrews et al., 2006; Braddock et al., 1963; Cots, 2008; Hudson, 2001; Myhill et al., 2012; Tomlinson, 1994; Vavre, 1996; Wyse, 2001). A recent content analysis of 238 empirical research studies involving Korean participants found that not one study involving Korean participants was published in the previous 20 years exploring this relationship between explicit grammar instruction and writing (Penn et al., 2013).

The purpose of this paper, therefore, is to begin addressing this gap in the literature by reporting on Korean learners' perceptions of the impact of explicit grammar instruction on their writing and editing abilities.

\section{Literature Review}

\subsection{The Great Grammar Debate}

The debate on the role of grammar in second or foreign language teaching is one that has been active since 
naturalistic language learning principles were first advocated by language specialists and linguistics scholars in the late 19th century. In 1884, German scholar F. Franke, in his publication, Die Praktische Spracherlernung auf Grund der Psychologic undder Physiologic der Sprache Dargestellt [Practical Language Learning, described on the Basis of the Psychology and Physiology of Language], called for the replacement of focus on explanation of grammar rules in the classroom by more direct use of the foreign language, whereby learners would be able to induce the grammar rules for themselves (Franke, 1984, cited in Richards \& Rodgers, 2001).

Nevertheless, owing to the strong dominance of Latin and Greek traditions in language learning and teaching, the supremacy of grammar in the language learning curriculum did not begin to suffer a serious decline until the mid-20th century, when the place of grammar in the language learning curriculum (i.e. not how grammar should be taught but whether grammar should be taught) began to be questioned. In his historical overview of the great grammar debate, Tonkyn (1994) attributes this decline to several principal causes, among which are: (a) the disillusionment of language teachers with linguistics, in general, as well as with traditional grammar; (b) the influence of sociolinguistics in broadening the notion of communicative competence to include a sociolinguistic dimension; and (c) the Communicative Language Teaching movement, which saw grammatical competence as but just one component of overall communicative competency.

In addition, the fields of applied linguistics, psychology and cognitive neuroscience, were independently seeing the evolution of the "theoretical dissociations between implicit and explicit knowledge of language" (N.C. Ellis, 2008: 119). In applied linguistics, the dissociation was made by Krashen (1982) with his Comprehensive Input Hypothesis. In psychology, the separation between implicit and explicit learning was achieved by Reber et al. (1976), who conducted an experiment among university subjects using a synthetic language and found that the subjects were able to detect the underlying rule system or 'grammar' of the foreign language more effectively when they were not consciously looking for it, thus separating implicit learning from explicit learning. Research in cognitive neuroscience discovered that explicit and implicit memories are stored in physically different parts of the brain (A.W. Ellis \& Young 1998, cited in N.C. Ellis 2008).

\subsection{Grammar and L2 Writing}

Thus, it may not be surprising that when we turn to examine the literature for the role of grammar in L2 writing instruction, we find that the studies investigating this connection have focused almost entirely on grammar instruction in the context of error feedback and correction. There are almost no studies save a handful few that have investigated the role of explicit grammar instruction in L2 writing, and most of these were limited to the study of learner perceptions. Zhou (2009) studied learner perceptions concerning the importance of improvement of grammar and vocabulary in their writing. The study found that these learners, who were enrolled in a pre-university intensive English for Academic Purposes program, did regard improvement of grammar and vocabulary in their writing to be an important personal goal to be met in language study. Another study of learner perceptions was conducted with respect to French as a foreign language. Manley \& Calk (1997) found that the majority of their participants perceived explicit, grammar instruction to be useful for their writing skills development. Finally, Klapper (1997, 1998) calls for greater explicit attention to grammar in the teaching and learning of German as a foreign language in American high schools.

As can be seen by this short list of articles, there appears to have been almost no interest in researching the role of explicit grammar instruction in second or foreign language writing, while interest in the role of corrective feedback in L2 writing has been abundant. It has been noted repeatedly that good, reliable evidence is wanting in this area of investigation (Andrews et al., 2006; Braddock et al., 1963; Cots, 2008; Hudson, 2001; Myhill et al., 2012; Tomlinson, 1994; Vavre, 1996; Wyse, 2001). Furthermore, a recent content analysis of 238 empirical research studies involving Korean participants found that not one study involving Korean participants was published in the previous 20 years exploring the relationship between grammar and writing (Penn et al., 2013).

Hence, the best information that we have at this time on the role of explicit grammar instruction in writing pedagogy comes from English as a mother tongue (L1) studies.

\subsection{Grammar and L1 Writing}

Here, we find that, up until recently, there have been two somewhat opposite trends in the U.S. and the U.K. In the U.S., Braddock et al. (1963) surveyed the academic literature on composition published up until that time and came to the conclusion that "instruction in formal grammar has little or no effect on the quality of student composition" and may even have "a harmful effect on the improvement of writing" (pp. 37-38). Martinsen (2000) notes that this report initiated a paradigmatic shift in the U.S. in writing instruction research, where the "focus in the writing classroom was no longer on the end product (i.e., the paper) but on the process by which the paper came to be" (p. 123).

In the U.K., however, there were calls for reform of a different kind during the 1960s. A research program directed by Michael Halliday was commissioned "to connect the work being done in linguistics with English language teaching" (Cots, 2008: 16). This investigation eventually led to the publication of two reports, the Kingman Report of 1988 and the Cox Report of 1989, which were together influential in the establishment of the Language in the National Curriculum (LINC) project, funded by the British government, to introduce language 
awareness as a subject in the school curriculum in response to declining standards of written English among high school graduates (ibid., 2008). Also influential in the U.K. was Carter's (1990) publication, Knowledge About Language and Curriculum: the LINC Reading, a collection of 16 essays designed to address language awareness issues for teachers in an accessible way, in which Carter associates the decline of explicit grammar teaching and disappearance of metalanguage from the classroom with disempowerment of learners, who are unable, as a result, to exercise "the kind of conscious control and conscious choice over language which enables both to see through language in a systematic way and to use language more discriminatingly" (p. 119).

Standards of L1 writing in schools have now become an international concern, with grammar being reintroduced in school curricula as a standards-raising measure in various parts of the world. In the U.S., the National Commission on Writing in America's Schools and Colleges (NCW) in their 2003 report called for national educational reform to address the problem of students' declining writing abilities, which was followed by the enactment of the national policy, "No Child Left Behind" (United States Department of Education, 2002). In Australia, the Minister for Schools acknowledged in the preface of the report of the 1996 National School English Literacy Survey, "that while some students are achieving high literacy standards, a disturbingly high number of Australian school children are failing to meet a minimum acceptable standard in literacy" (Masters and Forster, 1997).

Despite the attention that language pedagogues and researchers have given the place of grammar over the past decades and centuries, we find, oddly, that few quality studies have been conducted to understand better the role of explicit grammar instruction in writing pedagogy, even with respect to L1 writing. Andrews (2005) finds that "there is still a dearth of evidence for the effective use of grammar teaching of any kind in the development of writing" (p. 74). Andrews and his colleagues at The University of York had conducted two systematic research reviews, published by the Evidence for Policy and Practice Information and Coordinating Centre (EPPI-Centre), on the effectiveness of formal teaching of sentence grammar on the writing development of 5 to 16-year-olds (Andrews et al., 2004). Later in 2006, the two research reports were combined and published together in the British Educational Research Journal (Andrews et al., 2006). The reviews systematically examined relevant papers published in Canada, the US, the UK, Australia and New Zealand in English since 1900, and the results were somewhat inconclusive:

On the basis of the results of the two in-depth reviews, we can say, first, that the teaching of syntax (as part of a traditional or transformational/generative approach to teaching grammar) appears to have no influence on either the accuracy or quality of written language development for 5-16-year-olds. This does not mean to say that there could be no such influence. It simply means that there have been no significant studies to date that have proved such an effect" (p. 51).

In the U.S., Hudson's (2001) survey of the literature on writing concluded that "the idea that grammar teaching improves children's writing skills is much better supported by the available research than is commonly supposed" (p. 4). Both Tomlinson's (1994) and Andrews et al. (2006) note, however, that most of the research conducted in this area lack sufficient scientific rigor to offer any clear insights.

The most scientifically rigorous investigation into the effect of explicit grammar instruction in the development of writing skills was conducted in the context of English as a mother tongue by Myhill et al. (2012), involving 744 public school students in Year 8 in the U.K. Theirs was a national mixed-methods investigation with a randomized controlled quantitative arm, supplemented by a qualitative arm comprising teacher and student interviews and class observations, conducted among 31 schools in the south-west and the Midlands of England. The study found a highly significant positive difference for grammar instruction in terms of improvement in writing attainment.

Finally, closer to the Korean context, a recent survey of research on English writing involving Korean English learner participants found no studies investigating the link between explicit grammar instruction and writing skills (Penn et al., 2013).

Thus, there is some rigorous evidence that explicit grammar instruction may be beneficial for younger L1 learners' development of writing abilities. However, no data exist which could suggest whether that may also hold true for L2 learners. The purpose of this study is to begin the exploration into that question.

\section{Research Questions}

The study aims to address the question: Do learners perceive explicit sentence grammar instruction to be useful for writing and editing skills development? Specifically:

1. Do the participants perceive that the explicit sentence grammar instruction in the written form provided in this study has an impact on their writing skills?

2. Do the participants perceive that the explicit sentence grammar instruction in the written form provided in this study has an impact on their editing skills?

3. Do the participants perceive that the explicit sentence grammar instruction in the written form provided in this study has an impact on their partner's writing skills?

4. Do the participants perceive that the explicit sentence grammar instruction in the written form provided in this study has an impact on their partner's editing skills?

\section{Methodology}

\subsection{Participants and Setting}


Fifteen students of different majors at a university in Seoul participated in the study. As the university is one of the top-ranking universities in Korea, these students are considered to have studied intensively for the university entrance exams, in which English grammatical competence is featured highly (Choi, 2008). They were enrolled in an intermediate freshman English for Academic Purpose reading and writing course, but not all were freshman students; some were upperclassman students retaking this required freshman course. The course was held during the winter vacation semester, so the class met two hours a day, four times a week, for four weeks.

\subsection{The Procedure}

The participants completed a pre-intervention writing assignment, followed by the intervention, and then the post-intervention writing assignment. They were then asked to complete an online survey anonymously to reflect on the task overall. The participants formed pairs which they maintained throughout the duration of this study. That is, they kept the same partner for both pre-intervention and post-intervention writing assignments.

\subsubsection{Day 1}

Day 1 of the study coincided with Day 1 of the course, and the participants were introduced to the pre-intervention writing assignment (Assignment A). Twenty quotations prepared each on a folded piece of paper were placed in a bag provided by the instructor, and each pair pulled out one or two quotations from the bag at random, for a total of ten quotations to be used for Assignment A. The remaining quotations were kept to be used for the post-intervention assignment (Assignment B). The participants were given an opportunity to discuss and ask questions about the ten quotations in class before they were assigned Assignment A for homework. The assignment consisted of writing out their interpretation of each quotation, supported by an example, in at least 50 words per quotation, for a total word count of at least 500 words.

\subsubsection{Day 2}

On Day 2, the participants were guided through a self-revision and peer-revision process on their first drafts of the pre-intervention assignment. They then completed the second and final draft for homework.

\subsubsection{Days 3 through 6}

On Days 3 through 6, the participants received the intervention, which, on this winter vacation schedule, spanned the period of one week.

\subsubsection{Day 7}

On Day 7 , the participants were given an opportunity to discuss and ask questions about the remaining ten quotations and completed the first draft of Assignment B for homework. Assignment B was identical to Assignment
A, except that the ten quotations were different. The participants also kept the same partners that they had for Assignment A

\subsubsection{Day 8}

On Day 8, the participants were led through a self-revision and peer-revision process as before and completed the second and final draft of the assignment for homework.

Following completion of Assignment B, the participants were asked to fill out an online survey anonymously regarding their experience of the entire three-staged task involving Assignment A, the intervention, and Assignment B.

\subsection{The Intervention}

The intervention was provided in the form of a series of workbooks which the participants were asked to read. The series consisted of five workbooks, and the participants wrote one quiz for each workbook. The type of content contained in the books may be gleaned from the sample quiz questions provided in Appendix A). The quizzes were written as follows:

Day 3 - Workbook 1 Quiz: The Complete Sentence

Day 4 - Workbook 2 Quiz: Verb Tense

Day 5 - Workbook 3 Quiz: The Simple Sentence

Day 6 - Workbook 4 Quiz: The Compound Sentence

Day 7 - Workbook 5 Quiz: The Complex Sentence

It is estimated that each workbook takes the average student about 3-4 hours to complete. The purpose of the quizzes was simply to ensure that the participants had read and worked through the books. In addition, the books were checked to ensure that the participants had completed the exercises in the books. Aside from answering participants' questions on the contents of the workbooks, no other instruction or feedback on grammar or sentence structure was provided.

\subsection{The Survey Instrument}

The survey was conducted via a Google form, which the participants could access anonymously (Table 1). The questions were written in English, but the participants were invited to respond in English or Korean. The Likert Scale questions used a 4-point rating scale: No Difference, Slight Improvement, Good Improvement, Great Improvement.

The survey consisted of six questions. Questions 1 and 2 were general questions about the overall process of the task, from the Assignment A stage to the Assignment B stage. These questions were designed both to activate schema in preparation for the rest of the survey, and to collect qualitative data regarding the participants' overall experience of the task. Question 3 consisted of three Likert Scale sub-questions and one free-text sub-question. They were designed to collect data on the participants' perceptions regarding differences felt and noticed in their 
writing abilities between Assignment A and Assignment B. Question 4, like the second, consisted of three Likert Scale sub-questions and one free-text sub-question. They were designed to collect data on the participants' perceptions regarding differences felt and noticed in their partner's writing ability between Assignment A and Assignment B. Questions 5 and 6 were designed to collect data on the participants' perceptions regarding differences felt and noticed in their and their partner's editing ability

Table 1. Survey Instrument

\begin{tabular}{|c|c|c|c|c|}
\hline \multicolumn{5}{|c|}{ What do you think you learned as a result of this task? } \\
\hline \multicolumn{5}{|c|}{ How did you feel before, during and after the task? } \\
\hline \multicolumn{5}{|c|}{$\begin{array}{l}\text { Comparing your writing in Assignment A with your writing in } \\
\text { Assignment B, what differences have you noticed? }\end{array}$} \\
\hline & ND & $\mathrm{AL}$ & GD & GR \\
\hline $\begin{array}{l}\text { SENTENCE STRUCTURE } \\
\text { (E.g. number and quality of complete } \\
\text { sentences, variety of sentence types) }\end{array}$ & & & & \\
\hline $\begin{array}{l}\text { GENERAL ACCURACY (E.g. verb phrases, } \\
\text { punctuation, capitalization) }\end{array}$ & & & & \\
\hline $\begin{array}{c}\text { CLARITY OF EXPRESSION } \\
\text { (E.g. use of compound and complex } \\
\text { sentences to achieve greater clarity of } \\
\text { expression) }\end{array}$ & & & & \\
\hline
\end{tabular}

Please provide some more details regarding your answers.

Comparing your partner's writing in Assignment A with his/her writing in Assignment B, what differences have you noticed?

SENTENCE STRUCTURE

(E.g. number and quality of complete sentences, variety of sentence types)

GENERAL ACCURACY (E.g. verb phrases, punctuation, capitalization)

CLARITY OF EXPRESSION

(E.g. use of compound and complex

sentences to achieve greater clarity of expression)

Please provide some more details regarding your answers.

Comparing your ability to revise and edit your own and your partner's drafts of Assignment A and Assignment B, what differences have you noticed about your ability to revise and edit writing?

Your editing ability

Comparing your partner's comments and revisions on your drafts of Assignment A and Assignment B, what differences have you noticed about your partner's ability to revise and edit writing?

Partner's editing ability

Please provide some more details regarding your answer.

$\mathrm{ND}=$ No improvement, $\mathrm{AL}=\mathrm{A}$ little improvement, $\mathrm{GD}=\mathrm{Good}$ improvement, $\mathrm{GR}=$ Great improvement.

\subsection{Data Analysis}

Suitable to an exploratory study, the data was analyzed qualitatively. The outcome variable considered was the participants' perceptions of the impact of the intervention on: (i) their writing ability, (ii) their partner's writing ability, (iii) their editing ability, and (iii) their partner's editing ability. The Likert Scale questions were considered together with the associated free-text responses to formulate a subjective judgment as to whether the data indicate that the participant perceived the intervention to have had virtually no impact (VNI), or an impact (I), on: (i) their writing ability, (ii) their partner's writing ability, (iii) their editing ability, and (iii) their partner's editing ability. In addition, all of the free-text responses were examined to gain additional insights regarding the participants' perceptions of the impact of the intervention on their writing and editing abilities.

\section{Results}

\subsection{Overall Perceptions Re. Impact on Writing and Editing Abilities}

The overall perceptions of impact of the non-embedded, semi-contextualized explicit grammar instruction on writing and editing abilities are summarized in Table 2. Of the 15 participants, all participants appeared to have perceived some impact of the intervention on the improvement of their own writing abilities. All but one participant noticed an impact on their partners' abilities. The results were less unequivocal for perception of impact on editing abilities. Of the 15 participants, 11 seem to have noticed an impact on the improvement of their editing abilities, and 10 noticed an impact on their partner's editing abilities.

\subsection{Perceptions Re. Writing Abilities}

\subsubsection{Participants' Writing Abilities}

Regarding the participants' perceptions relating to improvement in their writing abilities, the results suggest that the majority of the students noticed at least a little improvement in their writing ability. Regarding sentence structure, 2/15 (13\%) participants reported noticing no difference, $6 / 15(40 \%)$ reported a little improvement, $6 / 15$ (40\%) reported good improvement, and 1/15 (7\%) reported great improvement. On general accuracy, 1/15 (7\%) reported no difference, $5 / 15(33 \%)$ reported a little improvement, $6 / 15$ (40\% reported good improvement, and $3 / 15(20 \%)$ reported great improvement. Concerning clarity of expression, $1 / 15(7 \%)$ reported no difference, $7 / 15(47 \%)$ reported a little improvement, 6/15 (40\%) reported good improvement, and 1/15 (7\%) reported great improvement. The three Likert Scale questions were considered together with the free text response to formulate a judgment as to whether the participant perceived that the intervention had virtually no impact (VNI) or an impact (I) on their writing ability. It was found that all $15 / 15(100 \%)$ of the participants seemed to perceive that the intervention had an impact on their writing ability (Table 1). 
Table 2. Perceptions of Impact

\begin{tabular}{|c|c|c|c|c|}
\hline \multirow{3}{*}{ Writing } & $\mathrm{n}$ & $\begin{array}{c}\text { Impact } \\
\text { (I) }\end{array}$ & $\begin{array}{c}\text { Virtually } \\
\text { No Impact } \\
\text { (VNI) }\end{array}$ \\
\cline { 2 - 5 } & Participant's & 15 & 15 & 0 \\
\hline \multirow{3}{*}{ Editing } & $\begin{array}{c}\text { Participant's } \\
\text { Partner's }\end{array}$ & 15 & 14 & 1 \\
\cline { 2 - 5 } & Participant's & 15 & 11 & 4 \\
\hline & $\begin{array}{c}\text { Participant's } \\
\text { Partner's }\end{array}$ & 15 & 10 & 5 \\
\hline
\end{tabular}

A closer examination of the free text responses suggests that the two areas that seemed to have the most impact for the participants from the intervention were sentence structure and mechanics. There was some dissatisfaction expressed by some participants on the lack of additional instruction or feedback from the teacher except to answer questions, during the intervention. The short time period of the intervention (one week) and need of additional practice as well as review of the books' contents were pointed out by some students to be constraints on improvement.

\subsubsection{Participants' Partner's Writing Abilities}

Regarding the participants' perceptions relating to improvement in their partners' abilities, the results suggest that the majority of the students noticed at least a little improvement in their partner's writing ability. On sentence structure, $1 / 15 \quad(7 \%)$ participants reported noticing no difference, $6 / 15(40 \%)$ reported a little improvement, $7 / 15$ (47\%) reported good improvement, and 1/15 (7\%) reported great improvement. On general accuracy, 2/15 (13\%) reported no difference, $5 / 15 \quad(33 \%)$ reported a little improvement, $6 / 15(40 \%)$ reported good improvement, and $2 / 15(13 \%)$ reported great improvement. Concerning clarity of expression, $0 / 15(0 \%)$ reported no difference, $8 / 15(53 \%)$ reported a little improvement, $7 / 15$ (47\%) reported good improvement, and 0/15 (0\%) reported great improvement. The three Likert Scale questions were considered together with the free text response to formulate a judgment as to whether the participant perceived that the intervention had virtually no impact (VNI) or an impact (I) on their partner's writing ability. The results suggest that $1 / 15 \quad(7 \%)$ participants perceived that the intervention had virtually no impact, and 14/15 (93\%), an impact, on their partner's writing ability (Table 1).

A closer examination of the free text responses suggests the following additional insights: The majority of the participants seemed to notice an improvement in their partner's writing post-intervention. Specifically, recurring comments mention increased clarity, ease of reading and comprehension of meaning and fewer errors.

\subsection{Perceptions Re. Editing Abilities}

\subsubsection{Participants' Editing Abilities}

Regarding the participants' perceptions relating to improvement in their editing abilities, the results suggest that most of the students noticed an improvement in their editing abilities. Of the 15 participants, 1 participant $(7 \%)$ reported no difference in their editing ability, 7 (47\%) reported a little improvement, $6(40 \%)$ reported good improvement, and $1(7 \%)$ reported great improvement. The Likert Scale question was taken together with the free text response to formulate a judgment as to whether the participant perceived that the intervention had virtually no impact (VNI) or an impact (I) on their partner's writing ability. The analysis suggests that 4/15 (27\%) perceived virtually no impact, while $11 / 15(73 \%)$ perceived an impact (Table 1).

A closer examination of the free text responses suggests the following additional insights: Most of the comments seem to support the Likert question finding that the participants perceived the intervention helpful for their editing abilities. In three cases, however, the comments that suggested minimal perception of impact were used to reinterpret the Likert Scale response of "A little improvement" as "Virtually No Impact."

\subsubsection{Participants' Partner's Editing Abilities}

Regarding the participants' perceptions relating to improvement in their partner's editing abilities, among the 15 participants, $2(13 \%)$ reported no difference in their partner's editing ability, $6(40 \%)$ reported a little improvement, 7 (47\%) reported good improvement, and 0 $(0 \%)$ reported great improvement. The Likert Scale question was taken together with the free text response to formulate a judgment as to whether the participant perceived that the intervention had virtually no impact (VNI) or an impact (I) on their partner's editing ability. The analysis suggests that $5 / 15$ (33\%) perceived virtually no impact, while 10/15 (67\%) perceived an impact.

A closer examination of the free text responses suggests the following additional insights: The comments at this final question were more difficult to interpret than the rest. It is likely that the participants may have been getting confused at this point of the survey by seemingly similar questions. Again, it was necessary to reinterpret three Likert Scale responses of "A little improvement" as "Virtually No Impact" based on the associated comments. One participant pointed out that sentence-level grammar was not sufficient in itself to improve entirely upon a draft.

\subsection{Overall Perceptions of the Task}

The evidence appears to be more unequivocal for perception of the intervention's impact on writing abilities than on editing abilities. Three participants consistently perceived that the intervention did not have an impact on either their own or their partner's editing abilities. One participant perceived virtually no improvement in his or her partner's writing or editing abilities.

An examination of the free-text responses to the general 
questions about the task overall, Questions 1 and 2 (Table 1), reveals that most of the participants expressed satisfaction with the review of grammar that they received in the intervention. One recurring theme is confidence, that gaining a firmer grasp of English grammar helped some participants to increase their confidence for writing in English. There was a range of language proficiencies in the group, and some found the intervention quite difficult while at least one participant found it somewhat easy.

\section{Discussion}

As a qualitative, exploratory study with a limited sample size and lack of control group, it is not possible to generalize the results beyond the sample group studied. Nevertheless, the results are striking in that they do suggest that non-embedded, semi-contextualized explicit grammar instruction provided in the form of a series of sentence grammar workbooks may have a potentially beneficial effect on university learners' perception of their writing and editing skills development. This finding is interesting, if not significant, for a number of reasons.

First, the type of explicit grammar instruction provided was not embedded in the way that it was in the Myhill et al. (2012) study. Neither was it entirely decontextualized, for research has shown that grammar instruction that is not closely related to writing instruction may not lead to gains in students' writing development (Chin, 2005). Rather, the workbooks were used in a semi-contextualized, non-embedded way, to address sentence grammar issues in the context of writing. Then, the instruction was immediately followed by application of what was learned in the writing process. The results of this study would seem to suggest, then, that even when the instruction is not tightly and seamlessly intertwined with writing instruction, there may be gains to be seen, at least from the students' perspective, when it is closely related to writing instruction.

Second, one of the limitations of embedded grammar instruction that Myhill et al. (2012) found is that it seems to be quite dependent on the teacher's linguistic subject knowledge (LSK). Where the teachers did not possess an effective grasp of the English grammar as a subject area, their students were less likely to benefit from their grammar instruction. Others have also voiced concerns about the declining level of LSK among language teachers (S. Andrews, 2003; Bartels, 2005; Cots, 2008; Hudson, 2004; Klapper, 1997, 1998; Leech, 1994). The results of this study suggest a possible means of addressing this issue of variability in teachers' LSK. By providing detailed grammar instruction relevant to the writing context in a compact written form, not only will grammar intervention vary less with teachers' LSK, but the teachers themselves will have an opportunity to raise their LSK quickly by working through the books, as well.

Third, it is significant to note that not a single participant in this particular cohort used the terms "boring" or "bored" in their free-text responses. Many noted that the written material was somewhat difficult and challenging, but no one seems to have found it boring or a waste of their study time. This suggests that it is actually possible to provide explicit grammar instruction in a written form that is not entirely devoid of interest or sense of relevance for learners.

Fourth, it is important also to note that, in order to control variables for the study, no other intervention was provided on the part of the teacher except to answer participants' questions about the books, and indeed, some of the students keenly felt the lack of the additional teacher involvement in this respect. Once the research study period had ended, however, this deficiency was subsequently rectified, and for the remaining duration of the course, the books were further used as a basis for teacher feedback on the students' writing. That is to say, the full impact of the intervention on students' perceptions could not be measured.

Lastly, as this study was conducted at one of the top-ranking universities in South Korea, we need to keep in view that virtually all of these students would have had ample grammar instruction during their middle school and high school years. Despite this fact, the majority of the participants seem to have perceived the remedial grammar instruction helpful and much needed. It is a common practice to overlook this need for remedial English grammar instruction in tertiary-level Korean education, but this study would suggest that it may be erroneous to assume that the English grammar study students undertake prior to university enrollment adequately prepares them for the demands of higher education learning.

\section{Conclusion}

In conclusion, this study explored qualitatively the effect of explicit grammar instruction on Korean students' perceptions of their writing and editing skills at the sentential level, in a group of 15 freshman students enrolled in an intermediate-level reading and writing course at a university in Seoul. The sentence grammar instruction was provided in the form of a set of workbooks, which the students read and studied for homework over a period of one week. Aside from answering students' questions on the workbooks, no other grammar instruction was provided. The results of a survey suggest that a positive impact of the intervention was perceived by a clear majority of the students regarding their writing skills as well as their editing skills. This study is significant for raising the possibility not only of non-embedded explicit grammar instruction having a beneficial role in foreign language writing pedagogy, but also of a beneficial role for grammar instruction in the form of self-study workbooks. As the study was quite limited in sample size and scope, further research is clearly needed to explore this relationship between explicit grammar instruction and writing development. 


\section{Appendix A: Sample Quiz Questions}

Workbook 1 Quiz: The Complete Sentence

In the following sentence: (i) put a vertical line between the subject and the predicate of the independent clause only; (ii) underscore the head noun of the subject with one line, and (iii) underscore the verb phrase with two lines (for the independent clause only).

According to official figures, a tiny British village has a higher birth rate than the world's five most densely populated countries.

Workbook 2 Quiz: Verb Tense

Write the correct verb phrases for each of the following. A man whose home (1) so full of garbage that he (2) to build an intricate network of tunnels to get around, (3) after losing his way in the garbage.

1. be, past simple, active voice

2. have, past simple, active voice

3. die, may with a perfect simple tense, active voice

Workbook 3 Quiz: The Simple Sentence

Write SS if it is a simple sentence and SF if it is a sentence fragment.

The study concluding that spit content does not vary much around the world, even given regional differences in diet.

\section{Workbook 4 Quiz: The Compound Sentence}

Which sentence can be changed to a sentence with a compound predicate?

(a) The wind was blowing, and the water was rough.

(b) Mr. Kwan and his son own a garage and they operate it.

Workbook 5 Quiz: The Complex Sentence

Combine the two sentences into a single complex sentence by changing the italicized sentence into an adjective clause. European beer is popular in Korea.

It has a higher alcohol content than local beers.

\section{REFERENCES}

[1] S. Andrews. 'Just like instant noodles': L2 teachers and their beliefs about grammar pedagogy, Teachers and Teaching, Vol.9, No.4, 351-375, 2003.

[2] R. Andrews. Knowledge about the teaching of [sentence] grammar: The state of play. English Teaching: Practice and Critique, Vol.4, No.3, 69-76, 2005.

[3] R. Andrews, C. Torgerson, S. Beverton, T. Locke, G. Low, A. Robinson, D. Zhu. The Effect of Grammar Teaching (Syntax) in English on 5 to 16 Year Olds' Accuracy and Quality in Written Composition, EPPI-Centre, University of London, London, 2004.

[4] R. Andrews, C. Torgerson, S. Beverton, A. Freeman, T. Locke, G. Low, D. Zhu. The effect of grammar teaching on writing development. British Educational Research Journal Vo.32, No.1, 39-55, 2006.

[5] N. Bartels. Applied Linguistics and Language Teacher
Education, Springer, New York, 2005.

[6] R. R. Braddock, R. Lloyd-Jones, L. Schoer. Research in Written Composition, National Council of Teachers of English Champaign, Illinois, 1963.

[7] R. Carter, Ed. Knowledge about Language and the Curriculum: The LINC Reader, Hodder and Stoughton, London, 1990.

[8] B. A. Chin. The Role of Grammar in Improving Student's Writing, Sadlier-Oxford, 2005.

[9] I.-C. Choi. The impact of EFL testing on EFL education in Korea. Language Testing, Vol.25, No.1, 39-62, 2008.

[10] J. M. Cots. Knowledge about language in the mother tongue and foreign language curricula. In J. Cenoz, N. H. Hornberger, Eds., Encyclopedia of Language and Education (Volume 6: Knowledge about Language), Springer, New York, 15-30, 2008.

[11] A. W. Ellis, A. W. Young. Human Cognitive Neuropsychology, Sussex, Erlbaum, Hove, 1988.

[12] N. C. Ellis. Implicit and explicit knowledge about language. In J. Cenoz, N. H. Hornberger. Eds., Encyclopedia of Language and Education (Volume 6: Knowledge about Language), Springer, New York, 119-31, 2008.

[13] F. Franke. Die Praktische Spracherlernung auf Grund der Psychologic undder Physiologic der Sprache Dargestellt [Practical Language Learning, described on the Basis of the Psychology and Physiology of Language],O. R. Reisland, Leipzig, 1884.

[14] R. Hudson. Grammar teaching and writing skills: The research evidence. Syntax in the Schools, Vol.17, No.1, 1-6, 2001.

[15] R. Hudson. Why education needs linguists (and vice versa). Journal of Linguistics. Vol. 40, No.1, 105-30, 2004.

[16] J. Klapper. Language learning at school and university: The great grammar debate continues (I). Language Learning Journal, Vol.16, No.1, 22-27, 1997.

[17] J. Klapper. Language learning at school and university: The great grammar debate continues (I). Language Learning Journal, Vol.18, No.1, 22-28, 1998.

[18] S. D. Krashen. Principles and Practice in Second Language Acquisition, Pergamon Press, Oxford, 1982.

[19] G. Leech. Students' grammar-teachers' grammarlearners' grammar. In Martin Bygate, Alan Tonkyn, and Eddie Williams, Ed., Grammar and the Language Teacher, Prentice Hall, Hemel Hempstead, 17-30, 1994.

[20] J. H. Manley, L. Calk. Grammar instruction for writing skills: Do students perceive grammar as useful? Foreign Language Annals, Vol.30, No.1, 73-83, 1997.

[21] A. Martinsen. The Tower of Babel and the teaching of grammar: Writing instruction for a new century. The English Journal , Vol.90, No.1, 122-26, 2000.

[22] G. N. Masters, M. Forster, Australian Council for Educational Research. Literacy Standards in Australia, Australian Council for Educational Research, Camberwell, Vic., 1997.

[23] D. A. Myhill, S. M. Jones, H. Lines, A, Watson. Re-thinking 
grammar: The impact of embedded grammar teaching on students' writing and students' metalinguistic understanding. Research Papers in Education, Vol.27, No.2, 139-66, 2012.

[24] S. Penn, E. H. Park, H.-W. Lim. A content analysis of empirical research on English writing using Korean subjects. English Language \& Literature Teaching, Vol.19, No.1, 203-228, 2013.

[25] A. S. Reber. Implicit learning of synthetic languages: The role of instructional set. Journal of Experimental Psychology: Human Learning and Memory, Vol.1, 88-94, 1976.

[26] J. C. Richards, T. S. Rodgers. Approaches and Methods in Language Teaching, Cambridge UP, Cambridge, 2001.

[27] D. Tomlinson. Errors in the research into the effectiveness of grammar teaching. English in Education, Vol.28, No.1, 20-26, 1994.
[28] A. Tonkyn. Introduction: Grammar and the language teacher. In M. Bygate, A. Tonkyn and E. Williams, Eds., Grammar and the Language Teacher, Prentice Hall, Hemel Hempstead, $1-14,1994$.

[29] United States Department of Education. No Child Left Behind (NCLB) Act of 2001. 2002.

[30] E. Vavra. On not teaching grammar. The English Journal, Vol.85, No.7, 32, 1996.

[31] D. Wyse. Grammar for writing? A critical review of empirical evidence. British Journal of Educational Studies, Vol.49, No.4, 411-427, 2001.

[32] A. A. Zhou. What adult ESL learners say about improving grammar and vocabulary in their writing for academic purposes. Language Awareness, Vol18, No.1, 31-46, 2009. 